\title{
Hematopoietic Stem Cell Expansion and Gene Therapy
}

\author{
Korashon Lynn Watts, $\mathbf{P h D}^{1}$, Jennifer Adair, $\mathbf{P h D}^{1}$, and Hans-Peter Kiem, $\mathbf{M D}^{1,2}$ \\ ${ }^{1}$ Fred Hutchinson Cancer Research Center, Seattle, WA, USA \\ ${ }^{2}$ University of Washington, Departments of Medicine \& Pathology, Seattle, WA, USA
}

\begin{abstract}
Hematopoietic stem cell (HSC) gene therapy remains a highly attractive treatment option for many disorders including hematologic conditions, immunodeficiencies including HIV/AIDS, and other genetic disorders like lysosomal storage diseases, among others. In this review, we discuss the successes, side effects, and limitations of current gene therapy protocols. In addition, we describe the opportunities presented by implementing ex vivo expansion of gene-modified HSCs, as well as summarize the most promising ex vivo expansion techniques currently available. We conclude by discussing how some of the current limitations of HSC gene therapy could be overcome by combining novel HSC expansion strategies with gene therapy.
\end{abstract}

\section{Keywords}

animal models; ex vivo expansion; gene therapy; stem cell

\section{INTRODUCTION}

Of the many past and current gene therapy clinical trials, hematopoietic stem cell (HSC) therapies remain among the most attractive gene therapy approaches, perhaps owing to clinical experience with HSC transplantation which has readily integrated ex vivo gene transfer protocols into current HSC transplantation practice. Advances in collection and isolation of hematopoietic stem cells from a variety of sources has promoted autologous gene therapy as a viable option for monogenic diseases of the blood and immune systems, storage disorders and selected disease conditions.

More than 20 years have passed since the first Recombinant DNA Advisory Committee (RAC)-approved human gene therapy clinical trial was carried out in 1989 by Rosenberg et al. (1). This was closely followed by the first therapeutic gene therapy clinical trial to treat severe combined immunodeficiency (SCID) by transferring the adenosine deaminase (ADA) gene into patient T-lymphocytes (2). Early success of gene therapy in SCID-X1 patients combined with the advent of protocols for improved transduction efficiency provided a platform for HSC gene therapy following low-dose conditioning with busulfan (3). This conditioning regimen was also found to support engraftment of gene-modified cells in the setting of ADA-SCID (4).

The two decades following these landmark studies have seen great progress. Over 1700 clinical trials have been or are being pursued in cancer, infectious diseases, and genetic

Corresponding author: Hans-Peter Kiem, MD Fred Hutchinson Cancer Research Center 1100 Fairview Avenue N D1-100 Seattle, WA 98109 hkiem@fhcrc.org .

Disclosure of Interests. The authors have no competing financial interests to disclose. 
diseases, with an average of approximately 100 new gene therapy clinical trials opening each year since $1999(5,6)$. During this time important developments have occurred in HSC expansion (7). Here, we review the current status of gene therapy in relation to HSC treatment and expansion strategies.

\section{SUCCESSES IN GENE THERAPY}

Gene therapy has seen several technological and biological breakthroughs in the last few decades. SCID-X1, ADA-SCID, and $\beta$-thalassemia are just a few of the hematologic disease conditions that have benefitted from gene therapy. One of the first HSC gene therapy successes was reported by Cavazzana-Calvo et al. in 2000 (8) detailing full correction of the SCID-X1 disease phenotype in gene therapy patients. This group recently presented the long-term outcomes for these patients, each of whom received autologous HSCs gene modified to express the cytokine receptor common $\gamma$ chain (9). Eight of nine patients were alive at an average follow-up period of 9 years. In surviving patients, gene therapy was successful at correcting the disorder, and gene-corrected T cells were detected for up to 10.7 years post-transplant. Seven patients had sustained immune reconstitution as well as normal thymopoiesis, and $\mathrm{T}$ cell receptor repertoire was diverse in all patients. Thus, gene therapy can be used to correct SCID-X1-related immunodeficiency, and for the majority of patients without an HLA-matched donor, it represents the best alternative treatment.

The outlook for ADA-SCID patients has also been improved by gene therapy. Over 30 patients have been treated for this disorder in the past decade using autologous, genemodified cells (4). Successes have included immune reconstitution, multilineage engraftment, systemic detoxification, restored thymic activity, and improved T cell function. Additionally, gene therapy for ADA-SCID offers a lower risk of gene therapy-related side effects (discussed below) compared to gene therapy for SCID-X1.

In the field of $\beta$-hemoglobinopathies, the most common inherited disorders, gene therapy is also making strides. Cavazzana-Calvo et al. (10) have shown transfusion independence of a patient with severe $\beta$-thalassemia nearly 3 years after transplant with gene-corrected autologous HSCs. Hitherto, this disorder has been difficult to treat with gene therapy because of the need for substantial hemoglobin production and the lack of a selective advantage for gene-modified cells. Recently Roselli et al. (11) reported correction of thalassemia major in cells of pediatric patients. The approach achieved high transduction efficiency, restored hemoglobin synthesis, reduced apoptosis, improved erythropoiesis, and maintenance of differentiation potential of gene-modified cells. Additionally, in vitro studies have shown no bias for vector integration in cancer-related genes, thus boding well for future clinical studies.

There are a growing number of phase I/II gene therapy clinical trials for a variety of hematologic and storage disorders including X-linked CGD, Wiskott-Aldrich syndrome, Fanconi anemia, adrenoleukodystrophy (ALD), and metachromatic leukodystrophy (MLD) (12).

\section{SIDE EFFECTS OF GENE THERAPY}

The early therapeutic success of the SCID-X1 and CGD trials was soon complicated by insertional mutagenesis, wherein clones harboring genotoxic vector insertions began expanding and eventually led to myelodysplastic syndrome (MDS) and, in some cases, leukemia. Specifically, four patients participating in the SCID-X1 trial developed leukemia after transplantation with gene-modified cells, likely because the IL2RG gene integrated next to a known cancer-causing gene (13). A clonal outgrowth of gene marked cells was also observed in patients undergoing gene therapy for X-linked CGD (14). Again, events 
were likely caused by insertion of the gene in or near proto-oncogenes (such as LMO2 or MDS1/EVI1), which are known to be precarious genomic locations. These adverse events highlight the complexity and intricacy of gene networks, making the outcomes associated with specific genetic insertion sites unpredictable.

\section{LIMITATIONS OF CURRENT GENE THERAPY PROTOCOLS}

Despite advances in HSC gene therapy, the lack of a registered gene-modified HSC drug emphasizes that many problems remain unsolved. Achieving a safe level of gene dosage and an effective therapeutic level of gene-modified HSCs in vivo remains one of the greatest challenges.

\section{Importance of a Selective Advantage}

In SCID, a single-gene dysfunction causes a developmental failure of the entire lymphoid cell lineage (15). Genetic correction of hematopoietic stem cells in this disease provides long-term repopulating cells with lymphopoietic differentiation capability and a lineagespecific selective advantage over mutant stem cells. This allows a very small number of gene-corrected cells to achieve a therapeutic effect, in some cases, even without a transplant preparative regimen $(16,17)$. Similarly, in an ADA-SCID gene therapy trial, discontinuation of enzyme replacement therapy following transplant of gene-modified HSCs promoted their selective survival over mutant counterparts (18). In contrast, in the setting of gene therapy for Fanconi anemia and Gaucher Disease, where no preparative regimen was used and no selective advantage for gene-modified cells was either present or implemented in vivo, therapeutic efficacy of HSC gene therapy fell short, compounded by early, inefficient transduction protocols $(19,20)$.

\section{Role of Pre-Transplant Conditioning}

One of the foremost limitations of current gene therapy protocols is the difficulty in striking the tenuous balance between in vivo selection of cells and pre-transplant conditioning. More specifically, if no preparative regimen is provided, gene-corrected cells must be conferred with a selective advantage in order to persist and function (for example, in SCID-X1 therapy). Conversely, if the cells do not exhibit a selective advantage, conditioning must be provided for effective gene therapy (for example, low-dose busulfan conditioning used in CGD trials) (3). However, pre-transplant conditioning with chemotherapy or radiation can be debilitating and may increase the likelihood of developing secondary malignancies (21). Increasing the number of gene-modified cells by ex vivo expansion may facilitate engraftment with less or no conditioning.

\section{Gene Therapy of Cord Blood Cells}

HSCs from certain sources such as umbilical cord blood (UCB) are very limited.

Nevertheless, UCB cells have the advantage of high repopulating efficiency, non-invasive method of collection, less stringent HLA matching requirement and ready availability in blood banks. Unfortunately many types of viral vectors have low transduction efficiency, further diminishing the numbers of cells available for transplant. An attractive strategy is therefore to combine ex vivo expansion with genetic manipulation of cord blood.

\section{EX VIVO EXPANSION OF HSCs}

Engraftment and safety of gene therapy protocols could be simultaneously improved if genemodified HSCs could be expanded and screened for integration sites prior to transplantation. Methods of ex vivo expansion currently being explored include the use of cytokines, copper chelators, exposure to signaling molecules, stromal support, and overexpression of 
transcription factors (Table I). The choice of expansion method often depends on technical considerations, as well as the nature of the cell population required. The most comprehensive approach may involve a combination of methods.

Cytokine cocktails are widely used to expand hematopoietic stem cells and many protocols are published or under exploration. Cytokines are necessary to induce cell expansion and maintain their survival in liquid culture. Cytokines under investigation include stem cell factor (SCF), thrombopoietin (TPO), and granulocyte colony-stimulating factor (G-CSF) $(22,23)$. De Lima et al. (23) adjusted this cocktail to expand cells of the myeloid lineage with SCF, TPO, G-CSF, flt-3 ligand (FL), and interleukin-6 (IL-6). Delaney et al. (24) studied SCF, FL, IL6, TPO, and interleukin-3 (IL3), in combination with the Notch ligand Delta (discussed later) to accelerate hematopoietic engraftment. SCF and TPO, used in most combinations, are perhaps the most essential components of the cocktail. A common problem with cytokine-induced HSC expansion is differentiation and loss of primitive phenotype. Some strategies have at least partially overcome this problem: The growth factor cocktail angiopoietin-like 5 (ANGPTL5), insulin growth factor binding protein 2 (IGFBP2), SCF, TPO, and fibroblast growth factor-1 (FGF-1) used by Lodish et al (25) induced a 20fold net expansion of repopulating cells from human cord blood. ANGPTL proteins belong to a family of secreted glycoproteins sharing limited sequence homology with angiopoietins (26). Other members of the ANGPTL family including angiopoietin-like 2 and angiopoietinlike 3 also result in HSC expansion, hinting at a functional role of these hormones in the generation of repopulating cells. The second key ingredient, IGFBP2, belongs to a family of proteins that bind IGF1 and IGF2 with an affinity greater than that of the IGF receptors, manipulating cell fate by controlling the activity of IGFs (27). The combination of these novel growth factors with the more traditional SCF, TPO and FL offers substantial promise.

Chelators such as tetraethylenepentamine (TEPA) bind and remove copper and expand hematopoietic stem and progenitor cells (28). De Lima et al. (23) have demonstrated the feasibility and success of TEPA to reduce the free copper content and lower oxidative stress on hematopoietic stem cells.

Another path to pursue in HSC expansion is to exploit signaling pathways such as Notch, a highly conserved signaling cascade. Delaney et al. (29) engineered an immobilized version of the Notch ligand Delta-1 to coat tissue-culture plates prior to expansion. Culture on this ligand substantially shortened the period of neutropenia after myeloablative cord blood transplantation in clinical trials (24). Most remarkably, increased lymphoid development was observed in direct relation to increasing Delta ligand concentration, thus providing a potential means to abbreviate the time required for lymphoid recovery following cord blood transplant.

Co-culture of hematopoietic stem cells on mesenchymal stromal cell (MSC) support is also promising. MSCs purified from the bone marrow provide a feeder layer that mimics the bone marrow microenvironment, providing an appropriate niche for hematopoietic stem cells. McNiece et al. (30) achieved a 10- to 20-fold increase in total nucleated cells, a 7- to 18 -fold increase in colony forming units (CFU), a 2- to 5-fold increase in primitive hematopoietic progenitors, and a 16- to 37-fold increase in CD34+ cells. Co-culturing HSCs on MSCs has the advantage of not requiring the isolation of CD34+ or CD133+ cells in order to expand primitive hematopoietic stem cells. Robinson et al. (31) currently use a 14day expansion of cord blood on MSCs. This strategy yields higher CD34+ cell doses than alternative methods, possibly because upfront CD34+ cell losses are avoided by culturing the unfractionated cord blood unit. This promising approach achieves neutrophil engraftment in 14 days and platelet engraftment in 35 days. Such studies have stimulated the need for a clinical grade off-the-shelf MSC product (31). 
Our laboratory has shown that HOXB4 has a differential effect on short- and long-term repopulating cells in a nonhuman primate transplantation model (32). In competitive repopulation assays we found that HOXB4 overexpression resulted in higher engraftment in all animals. The influence of HOXB4 is most obvious early after transplant, resulting in 56fold higher engraftment of HOXB4 cells compared to control cells. Furthermore, at 6 months post-transplant, the number of cells expressing HOXB4 remained 5-fold higher than controls. A recombinant TAT-HOXB4 protein has been developed (33) with proven efficacy in expanding hematopoietic stem cells; however, the short half-life of this protein presents technical difficulties. Additional work focuses on developing a more stable HOXB4 protein.

Recently, the aryl hydrocarbon receptor inhibitor termed StemRegenin1 (SR1) was reported to induce HSC expansion in culture (7). This purine derivative prevailed among thousands of heterocycles tested as a cell culture media additive to expand primitive HSCs. Inhibition of the aryl hydrocarbon receptor, a ligand-activated transcription factor, appears to persuade cells to undergo self-renewal in lieu of differentiation, but the exact mechanism is unknown. Culture of adult mobilized peripheral blood and UCB stem cells in the range of 0.75 to 1.0 uM SR1 resulted in a 50-fold increase in CD34+ cells and 17-fold increase in NOD/SCID repopulating cells. Both early engraftment and late engraftment of myeloid (CD11b and CD33) and lymphoid (CD19 and CD3) cells was enhanced. A commercial version of StemRegenin1 is now available from Cellagen Technology.

Combinations of expansion techniques often yield the best results, as many of these techniques synergize to expand more than one population of cells. Extending our previous findings that HOXB4 increases generation of hematopoietic progenitors, we added Delta-1 ligand to cultures of HOXB4-transduced cells. We were then able to expand lymphoid and megakaryocytic lineages (not observed with HOXB4 alone) (34). Cord blood cells from macaque and human subjects were transduced with a HOXB4-expressing gammaretroviral vector and cultured in the presence of immobilized Delta-1 ligand. The inclusion of Delta-1 ligand in vitro yielded higher numbers of CD34+ and CD7+ cells than non-Delta cultures. Expansion of HOXB4-transduced cells with Delta ligand resulted in a higher number of NOD/SCID repopulating cells of the CD45+, CD34+, CD3+, CD20+, and CD41+ lineage than in cultures of either factor alone. It is likely that other combinations of expansion techniques will synergize as well to promote HSC growth. Furthermore, reporter gene (YFP or GFP) markers have contributed immensely to the field and simplified competitive repopulation assays, allowing researchers to individually track the contributions of distinct populations of cells in vivo.

\section{LIMITATIONS OF CURRENT HSC EXPANSION STUDIES}

The merging of ex vivo expansion and gene therapy has yielded both successes and failures. However, most advances are restricted to murine models. We showed in 2003 that distinct HSC populations are responsible for hematopoietic repopulation in NOD/SCID mice and nonhuman primates (35). A comparison of engraftment levels in both of these animal models revealed that the NOD/SCID model is not a conducive archetype for read-out of long-term repopulating cells. Though the NOD/SCID IL2R gamma null (NSG) mouse is a significant advance (36), true long-term, multilineage engraftment can still only be tested in a large-animal model.

One of the earlier studies which proved the usefulness of transducing and expanding cell grafts was performed by Piacibello et al. (37). This group studied the engraftment of human cord blood CD34+ cells transduced with a GFP-expressing lentiviral vector versus control, non-transduced cells in NOD/SCID mice. They showed similar CD34+ expansion over 4 weeks in culture, thus indicating that genetic manipulation did not hinder the repopulating 
ability of the cells. Furthermore, mice receiving transduced and expanded cells showed higher levels of human engraftment than mice receiving grafts of transduced, non-expanded cells, demonstrating improved engraftment kinetics following ex vivo expansion.

Impressively, they identified $\mathrm{GFP}^{+}$cells in secondary and tertiary murine recipients; $20 \%$ of human cells were $\mathrm{GFP}^{+}$in secondary recipients and $15 \%$ of human cells were $\mathrm{GFP}^{+}$in tertiary recipients, suggesting the sustainability of gene-marked cells. Integration analysis demonstrated that the $\mathrm{GFP}^{+}$cells were from a polyclonal population, providing more evidence of the safety of ex vivo expansion of gene-modified cells. In conclusion, the Piacibello studies provided important data regarding the ability to transduce, expand, and maintain self-renewal in hematopoietic stem cells.

Unfortunately, the difficulty of finding factors and combinations that result in true expansion of HSCs is demonstrated by the lack of any successful translation to large animal studies and patients. For example, Tisdale et al. (38) compared engraftment in rhesus macaques of peripheral blood progenitors transduced and expanded for 10 to 14 days and those transduced and not expanded. They determined that ex vivo expansion led to a 5- to 13-fold higher cell and CFU dose; however, short-term and long-term marking were severely lower when expanded cells were transplanted compared to transplant of non-expanded cells. Transplant of non-expanded cells resulted in around $10 \%$ to $20 \%$ gene marking in the animals, compared to only around $0.01 \%$ gene marking from expanded cells. There are several explanations for these unfavorable findings. First, the use of peripheral blood instead of the more stem cell-rich bone marrow or cord blood used in other studies may have contributed. Alternatively, the ex vivo culture media used (containing combinations of IL-3, IL-6 SCF, FL, and autologous stroma) may not have been ideal for peripheral blood-derived stem cells. In any event, it is curious that cell dose and CFU dose were higher in expanded grafts, yet this difference was not reflected in vivo. Regarding drawbacks of ex vivo cell expansion, it is also important to keep in mind that prolonged periods of culture promote repeated cell divisions, which may increase the likelihood of spontaneous mutations in cells (39).

In summary, though engraftment of ex vivo expanded, gene-modified cells can be routinely achieved in NOD/SCID mice (37), successful long-term engraftment of ex vivo expanded, gene-modified cells has not been shown in large animal models or humans. Thus, appropriate clinical expansion protocols are still lacking. Other obstacles are the risk of myeloid leukemia in large-animal models transplanted with HOXB4-expanded cells (40) and cytogenetic abnormalities from prolonged cell culture (41).

\section{ADVANTAGES OF COMBINING GENE TRANSFER AND HSC EXPANSION}

\section{Reduced Conditioning}

Research in mice provides encouraging evidence that infusing higher numbers of cells allows for lower intensity pre-transplant conditioning. For a time, it was widely believed that in order for stem cells to engraft in a bone marrow transplant model, significant doses of irradiation had to be given to make marrow space. In 1968 Micklem et al. investigated this long-held belief by injecting 10 million cells into normal non-irradiated mice. At sacrifice 1 to 12 weeks post-transplant, all mice had donor-derived cells in the bone marrow and the majority also had donor-derived cells in the spleen and lymph nodes (42). Later Brecher et al. (43) and Saxe et al. (44) observed successful engraftment from relatively high cell numbers in normal, non-conditioned murine hosts. Furthermore, Quesenberry and colleagues showed persistent engraftment in nonmyeloablated mice up to 2 years posttransplant in the thymus, spleen, and bone marrow (45). This group concluded that a single infusion of gene-modified cells at a high enough dose may be sufficient in the normal, unprepared host for therapeutic effect (46). Similarly, in gene therapy studies involving 
canine subjects, cells expanded long-term in Dexter culture (i.e., HSCs co-cultured in the presence of a stromal layer) were infused into non-myeloablated dogs; the progeny were detected up to 2 years later, supporting the idea that the functional state of transplanted cells is of higher significance than the degree of conditioning (47). It is now known that the endothelial barriers are damaged by radiation, and that the passage of cells through a damaged endothelium may impair their ability to self renew and may shorten their life span, supporting the idea that decreasing conditioning may be advantageous (48). Therefore, in the setting of non-myeloablative transplant, ex vivo expansion can be used to increase genemodified cells to numbers high enough to compete with endogenous host cells. Nonmyeloablative conditioning is becoming increasingly popular, as it broadens the patient pool to include patients who are older or who have pre-existing co-morbidity. These milder conditioning regimens do not eliminate all remaining host cells; thus, an expanded graft of gene-modified cells can help boost donor contribution and overpower residual autologous cells.

\section{Improved Safety}

Ex vivo expansion of gene-modified HSCs not only improves transplant success by increasing cell numbers, but also improves safety, buying time for pre-administration screening to identify mutagenic integration sites in transduced cells. In the SCID-X1 and CGD cases, it was only after transplant that the delicate nature of the mutagenic integration site and the resulting clonal outgrowth were discovered.

\section{Pre-Infusion Selection and Expansion}

An approach allowing the selection of an HSC product containing a very high level of genemodified (i.e. corrected) HSCs could obviate the need for in vivo selection and the exposure of patients to chemotherapy. The gene-modified cells can be selected in vitro by the addition of a second, selectable gene in addition to the therapeutic gene. Selectable transgenes include mutant forms of the methylguanine methyltransferase (MGMT) gene, notably the P140K and G156Amutants (49). In the presence of cytotoxic drugs, these mutant genes confer a selective advantage to transduced cells. This strategy, while promising, brings several concerns. First, there is little evidence suggesting that HSCs will tolerate ex vivo cytotoxic drug exposure and the timing of this drug exposure may need to be carefully evaluated with regard to the kinetics of transgene expression following transduction. Second, the engraftment capability of transduced cells exposed to cytotoxic agents ex vivo is not known. Finding a balance between a selective dose of the desired cytotoxic agent, the timing of drug exposure and recovery prior to infusion, in addition to preserving the integrity of the gene-modified cell pool, may prove too complex to facilitate this approach clinically.

\section{PRE-CLINICAL MODELS FOR STUDYING HSC GENE THERAPY/ EXPANSION}

Murine models, valuable for studying retroviral transduction, short-term engraftment kinetics, and multi-lineage repopulation are not suitable for long-term safety and follow-up studies owing to their relatively short life span (35). Differences between mouse and human host cell receptors, cell-cycle status, and engraftment kinetics make it difficult to draw clinically relevant mouse-to-human comparisons (50). Furthermore, there are differences in the clonality of cells capable of repopulating the hematopoietic system and variation in what constitutes "myeloablative conditioning". Studies in dogs or nonhuman primates offer better preclinical models, especially for HSC-related protocols. Characterization of the dog leukocyte antigen has improved the canine model of allogeneic bone marrow transplantation, allowing researchers to study transplantation with various degrees of donor/ 
recipient mismatch (51). However, the nonhuman primate is probably the most applicable large-animal model for hematopoietic gene therapy and expansion studies (Figure 1).

Because of the overwhelming homology between humans and nonhuman primates, nearly all the human cytokines and growth factors are functional in this model. In addition, one of the most frequently studied diseases, AIDS, can be modeled in the nonhuman primate. Similarities between nonhuman primates and humans allow utilization of the same posttransplant drugs and therapeutic regimens. Finally, in the field of genetic manipulation and ex vivo expansion of cord blood CD34+ cells, the similar parity rates and the low frequency of multiple births in nonhuman primates allows direct translation to the human setting.

\section{FUTURE PROSPECTS}

The future of ex vivo expansion and gene therapy is promising. Improved ex vivo expansion and gene therapy should pave the way for advancements in cord blood transplant, nonmyeloablative transplant, safety screening, and therapy for specific diseases such as Fanconi anemia or thalassemia, where reduced numbers of HSCs with no conferred selective advantage have limited the success of gene therapy. Future research may even make it possible to weed out specific clones and only expand those deemed "safe".

\section{Acknowledgments}

This work was supported in part by NIH grants AI080326, DK56465, CA114218, HL084345, HL03644, HL092554, and HL098489. We thank Bonnie Larson and Helen Crawford for help in preparing the manuscript. H.P. Kiem is a Markey Molecular Medicine Investigator and the recipient of the José Carreras/E. Donnall Thomas Endowed Chair for Cancer Research.

\section{Abbreviations}

$\begin{array}{ll}\text { ADA } & \text { adenosine deaminase } \\ \text { ALD } & \text { adrenoleukodystrophy } \\ \text { ANGPTL5 } & \text { angiopoietin-like 5 } \\ \text { CFU } & \text { colony forming units } \\ \text { CGD } & \text { chronic granulomatous disease } \\ \text { G-CSF } & \text { granulocyte colony-stimulating factor } \\ \text { FGF-1 } & \text { fibroblast growth factor-1 } \\ \text { FL } & \text { flt-3 ligand } \\ \text { HSC } & \text { hematopoietic stem cell } \\ \text { IGFBP2 } & \text { insulin growth factor binding protein 2 } \\ \text { IL-3 } & \text { interleukin-3 } \\ \text { IL-6 } & \text { interleukin-6 } \\ \text { MDS } & \text { myelodysplastic syndrome } \\ \text { MGMT } & \text { methylguanine methyltransferase } \\ \text { MLD } & \text { metachromatic leukodystrophy } \\ \text { MSC } & \text { mesenchymal stromal cell } \\ \text { NSG } & \text { NOD/SCID IL2R gamma null } \\ \text { RAC } & \text { Recombinant DNA Advisory Committee }\end{array}$




$\begin{array}{ll}\text { SCF } & \text { stem cell factor } \\ \text { SCID } & \text { severe combined immunodeficiency } \\ \text { SR1 } & \text { StemRegenin1 } \\ \text { TEPA } & \text { tetraethylenepentamine } \\ \text { TPO } & \text { thrombopoietin } \\ \text { UCB } & \text { umbilical cord blood }\end{array}$

\section{REFERENCES}

1. Rosenberg SA, Aebersold P, Cornetta K, Kasid A, Morgan RA, Moen R, et al. Gene transfer into humans - immunotherapy of patients with advanced melanoma, using tumor-infiltrating lymphocytes modified by retroviral gene transduction. N Engl J Med. 1990; 323:570-8. [PubMed: 2381442]

2. Blaese RM, Culver KW, Miller AD, Carter CS, Clerici M, Shearer G, et al. T lymphocyte-directed gene therapy for ADA-SCID; initial trial results after 4 years. Science. 1995; 270:475-80. [PubMed: 7570001]

3. Ott MG, Schmidt M, Schwarzwaelder K, Stein S, Siler U, Koehl U, et al. Correction of X-linked chronic granulomatous disease by gene therapy, augmented by insertional activation of MDS1EVI1, PRDM16 or SETBP1. Nat Med. 2006; 12:401-9. [PubMed: 16582916]

4. Ferrua F, Brigida I, Aiuti A. Update on gene therapy for adenosine deaminase-deficient severe combined immunodeficiency (Review). Current Opinion in Allergy \& Clinical Immunology. 2010; 10:551-6. [PubMed: 20966749]

5. Lee B, Davidson BL. Gene therapy grows into young adulthood: special review issue. Hum Mol Genet. 2011; 20:R1. [PubMed: 21571785]

6. Denefle PP. Introduction to gene therapy: a clinical aftermath. Methods in Molecular Biology. 2011; 737:27-44. [PubMed: 21590392]

7. Boitano AE, Wang J, Romeo R, Bouchez LC, Parker AE, Sutton SE, et al. Aryl hydrocarbon receptor antagonists promote the expansion of human hematopoietic stem cells. Science. 2010; 329:1345-8. [PubMed: 20688981]

8. Cavazzana-Calvo M, Hacein-Bey S, de Saint Basile G, Gross F, Yvon E, Nusbaum P, et al. Gene therapy of human severe combined immunodeficiency (SCID)-X1 disease. Science. 2000; 288:66972. [PubMed: 10784449]

9. Hacein-Bey-Abina S, Hauer J, Lim A, Picard C, Wang GP, Berry CC, et al. Efficacy of gene therapy for X-linked severe combined immunodeficiency. N Engl J Med. 2010; 363:355-64. [PubMed: 20660403]

10. Cavazzana-Calvo M, Payen E, Negre O, Wang G, Hehir K, Fusil F, et al. Transfusion independence and HMGA2 activation after gene therapy of human - thalassaemia. Nature. 2010; 467:318-22. [PubMed: 20844535]

11. Roselli EA, Mezzadra R, Frittoli MC, Maruggi G, Biral E, Mavilio F, et al. Correction of betathalassemia major by gene transfer in haematopoietic progenitors of pediatric patients. EMBO molecular medicine. 2010; 2:315-28. [PubMed: 20665635]

12. Naldini L. Ex vivo gene transfer and correction for cell-based therapies (Review). Nat Rev Genet. 2011; 12:301-15. [PubMed: 21445084]

13. Hacein-Bey-Abina S, Garrigue A, Wang GP, Soulier J, Lim A, Morillon E, et al. Insertional oncogenesis in 4 patients after retrovirus-mediated gene therapy of SCID-X1. J Clin Invest. 2008; 118:3132-42. [PubMed: 18688285]

14. Stein S, Ott MG, Schultze-Strasser S, Jauch A, Burwinkel B, Kinner A, et al. Genomic instability and myelodysplasia with monosomy 7 consequent to EVI1 activation after gene therapy for chronic granulomatous disease. Nat Med. 2010; 16:198-204. [PubMed: 20098431] 
15. Notarangelo LD. Primary immunodeficiencies (Review). Journal of Allergy \& Clinical Immunology. 2010; 125:S182-S194. [PubMed: 20042228]

16. Aiuti A, Roncarolo MG. Ten years of gene therapy for primary immune deficiencies (Review). Hematology. 2009:682-9. [PubMed: 20008254]

17. Fischer A, Hacein-Bey-Abina S, Cavazzana-Calvo M. 20 years of gene therapy for SCID. Nat Immunol. 2010; 11:457-60. [PubMed: 20485269]

18. Aiuti A, Slavin S, Aker M, Ficara F, Deola S, Mortellaro A, et al. Correction of ADA-SCID by stem cell gene therapy combined with nonmyeloablative conditioning. Science. 2002; 296:2410-3. [PubMed: 12089448]

19. Liu JM, Kim S, Read EJ, Futaki M, Dokal I, Carter CS, et al. Engraftment of hematopoietic progenitor cells transduced with the Fanconi anemia group C gene (FANCC). Hum Gene Ther. 1999; 10:2337-46. [PubMed: 10515453]

20. Sidransky E, LaMarca ME, Ginns EI. Therapy for Gaucher disease: don't stop thinking about tomorrow (Review). Molecular Genetics \& Metabolism. 2007; 90:122-5. [PubMed: 17084653]

21. Bolling T, Kreuziger DC, Ernst I, Elsayed H, Willich N. Retrospective, monocentric analysis of late effects after Total Body Irradiation (TBI) in adults. Strahlentherapie und Onkologie. 2011; 187:311-5. [PubMed: 21533759]

22. Shpall EJ, Quinones R, Giller R, Zeng C, Baron AE, Jones RB, et al. Transplantation of ex vivo expanded cord blood. Biol Blood Marrow Transplant. 2002; 8:368-76. [PubMed: 12171483]

23. de Lima M, McMannis J, Gee A, Komanduri K, Couriel D, Andersson BS, et al. Transplantation of ex vivo expanded cord blood cells using the copper chelator tetraethylenepentamine: a phase I/II clinical trial. Bone Marrow Transplant. 2008; 41:771-8. [PubMed: 18209724]

24. Delaney C, Heimfeld S, Brashem-Stein C, Voorhies H, Manger RL, Bernstein ID. Notch-mediated expansion of human cord blood progenitor cells capable of rapid myeloid reconstitution. Nat Med. 2010; 16:232-7. [PubMed: 20081862]

25. Zhang CC, Kaba M, Iizuka S, Huynh H, Lodish HF. Angiopoietin-like 5 and IGFBP2 stimulate ex vivo expansion of human cord blood hematopoietic stem cells as assayed by NOD/SCID transplantation. Blood. 2008; 111:3415-23. [PubMed: 18202223]

26. Oike Y, Yasunaga K, Suda T. Angiopoietin-related/angiopoietin-like proteins regulate angiogenesis (Review). Int J Hematol. 2004; 80:21-8. [PubMed: 15293564]

27. Ranke MB, Elmlinger M. Functional role of insulin-like growth factor binding proteins (Review). Horm Res. 1997; 48(Suppl. 4):9-15. [PubMed: 9350439]

28. Prus E, Fibach E. The effect of the copper chelator tetraethylenepentamine on reactive oxygen species generation by human hematopoietic progenitor cells. Stem Cells \& Development. 2007; 16:1053-6. [PubMed: 18047399]

29. Delaney C, Varnum-Finney B, Aoyama K, Brashem-Stein C, Bernstein ID. Dose-dependent effects of the Notch ligand Delta1 on ex vivo differentiation and in vivo marrow repopulating ability of cord blood cells. Blood. 2005; 106:2693-9. [PubMed: 15976178]

30. McNiece I, Harrington J, Turney J, Kellner J, Shpall EJ. Ex vivo expansion of cord blood mononuclear cells on mesenchymal stem cells. Cytotherapy. 2004; 6:311-7. [PubMed: 16146883]

31. Robinson SN, Simmons PJ, Yang H, Alousi AM, Marcos dL, Shpall EJ. Mesenchymal stem cells in ex vivo cord blood expansion (Review). Bailliere's Best Practice in Clinical Haematology. 2011; 24:83-92.

32. Zhang X-B, Beard BC, Beebe K, Storer B, Humphries RK, Kiem H-P. Differential effects of HOXB4 on nonhuman primate short- and long-term repopulating cells. PLoS Medicine. 2006; 3 DOI: 10.1371/journal.pmed.0030173.

33. Krosl J, Austin P, Beslu N, Kroon E, Humphries RK, Sauvageau G. In vitro expansion of hematopoietic stem cells by recombinant TAT-HOXB4 protein. Nat Med. 2003; 9:1428-32. [PubMed: 14578881]

34. Watts KL, Delaney C, Humphries RK, Bernstein I, Kiem H-P. Combination of HOXB4 and delta-1 ligand improves expansion of cord blood cells. Blood. 2010; 116:5859-66. [PubMed: 20921340] 
35. Horn PA, Thomasson BM, Wood BL, Andrews RG, Morris JC, Kiem H-P. Distinct hematopoietic stem/progenitor cell populations are responsible for repopulating NOD/SCID mice compared with nonhuman primates. Blood. 2003; 102:4329-35. [PubMed: 12816869]

36. Shultz LD, Lyons BL, Burzenski LM, Gott B, Chen X, Chaleff S, et al. Human lymphoid and myeloid cell development in NOD/LtSz-scid IL2R gamma null mice engrafted with mobilized human hemopoietic stem cells. J Immunol. 2005; 174:6477-89. [PubMed: 15879151]

37. Piacibello W, Bruno S, Sanavio F, Droetto S, Gunetti M, Ailles L, et al. Lentiviral gene transfer and ex vivo expansion of human primitive stem cells capable of primary, secondary, and tertiary multilineage repopulation in NOD/SCID mice. Nonobese diabetic/severe combined immunodeficient. Blood. 2002; 100:4391-400. [PubMed: 12453876]

38. Tisdale JF, Hanazono Y, Sellers SE, Agricola BA, Metzger ME, Donahue RE, et al. Ex vivo expansion of genetically marked Rhesus peripheral blood progenitor cells results in diminished long-term repopulating ability. Blood. 1998; 92:1131-41. [PubMed: 9694700]

39. Guy K, Middleton PG, Bansal NS, Ross JA, Steel CM. Recurrent mutation of immunoglobulin and c-myc genes and differential expression of cell surface antigens occur in variant cell lines derived from a Burkitt lymphoma. Int J Cancer. 1990; 45:109-18. [PubMed: 2298494]

40. Zhang X-B, Beard BC, Trobridge GD, Wood BL, Sale GE, Sud R, et al. High incidence of leukemia in large animals after stem cell gene therapy with a $H O X B 4$-expressing retroviral vector. J Clin Invest. 2008; 118:1502-10. [PubMed: 18357342]

41. Li X, Le Beau MM, Ciccone S, Yang FC, Freie B, Chen S, et al. Ex vivo culture of Fancc-/- stem/ progenitor cells predisposes cells to undergo apoptosis, and surviving stem/progenitor cells display cytogenetic abnormalities and an increased risk of malignancy. Blood. 2005; 105:3465-71. [PubMed: 15644418]

42. Micklem HS, Clarke CM, Evans EP, Ford CE. Fate of chromosome-marked mouse bone marrow cells tranfused into normal syngeneic recipients. Transplantation. 1968; 6:299-302. [PubMed: 5654091]

43. Brecher G, Ansell JD, Micklem HS, Tjio JH, Cronkite EP. Special proliferative sites are not needed for seeding and proliferation of transduced bone marrow cells in normal syngeneic mice. Proc Natl Acad Sci USA. 1982; 79:5085-7. [PubMed: 6750615]

44. Saxe DF, Boggs SS, Boggs DR. Transplantation of chromosomally marked syngeneic marrow cells into mice not subjected to hematopoietic stem cell depletion. Exp Hematol. 1984; 12:277-83. [PubMed: 6370711]

45. Stewart FM, Crittenden RB, Lowry PA, Pearson-White S, Quesenberry PJ. Long-term engraftment of normal and post-5-fluorouracil murine marrow in normal nonmyeloablated mice. Blood. 1993; 81:2566-71. [PubMed: 8098231]

46. Ramshaw HS, Crittenden RB, Dooner M, Peters SO, Rao SS, Quesenberry PJ. High levels of engraftment with a single infusion of bone marrow cells into normal unprepared mice. Biol Blood Marrow Transplant. 1995; 1:74-80. [erratum appears in Biol Blood Marrow Transplant 1996 Feb; 2(1):54]. [PubMed: 9118295]

47. Bienzle D, Abrams-Ogg AC, Kruth SA, Ackland-Snow J, Carter RF, Dick JE, et al. Gene transfer into hematopoietic stem cells: long-term maintenance of in vitro activated progenitors without marrow ablation. Proc Natl Acad Sci USA. 1994; 91:350-4. [PubMed: 8278392]

48. Brecher G, Neben S, Yee M. Bone marrow proliferation after passage through an irradiated host. Prog Clin Biol Res. 1990; 352:449-58. [PubMed: 1976259]

49. Neff T, Beard BC, Kiem H-P. Survival of the fittest: in vivo selection and stem cell gene therapy (Review). Blood. 2006; 107:1751-60. [PubMed: 16269617]

50. Trobridge GD, Kiem H-P. Large animal models of hematopoietic stem cell gene therapy. Gene Ther. 2010; 17:939-48. [PubMed: 20428209]

51. Venkataraman GM, Stroup P, Graves SS, Storb R. An improved method for dog leukocyte antigen 88 typing and two new major histocompatibility complex class I alleles, DLA-88*01101 and DLA-88*01201. Tissue Antigens. 2007; 70:53-7. [PubMed: 17559581] 


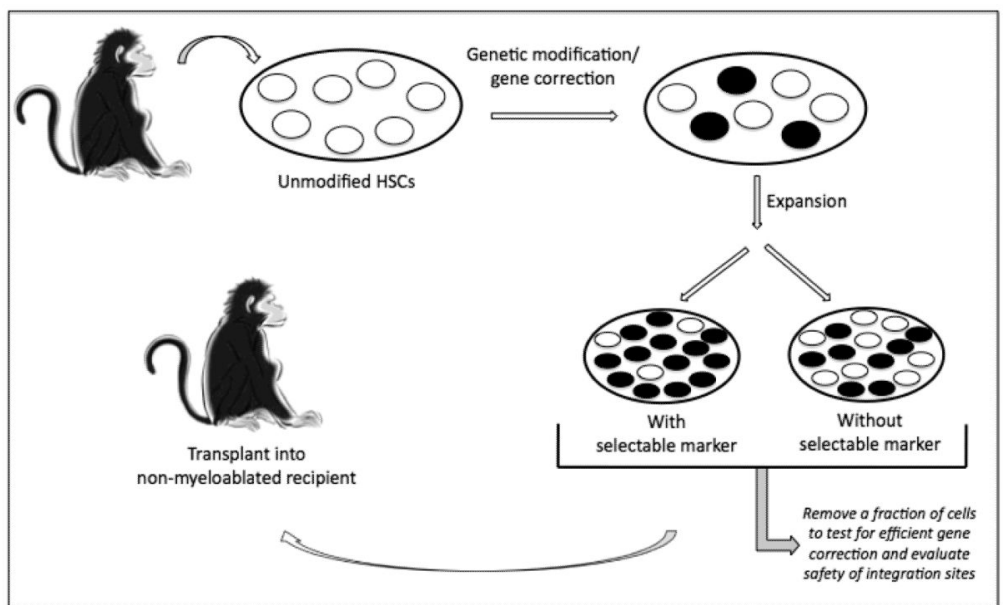

Figure 1. Schematic representation of ex vivo expansion of gene-modified cells in a nonhuman primate model

Bone marrow, peripheral blood, or cord blood hematopoietic stem cells (HSCs) are removed from the monkey for ex vivo manipulation. Cells are gene-modified in vitro and expanded. Prior to infusion, a sample of the cells is tested to determine efficiency of gene correction and safety of the integration site profile. If cells pass this quality-control checkpoint, they are transplanted back into the non-myeloablated monkey. 


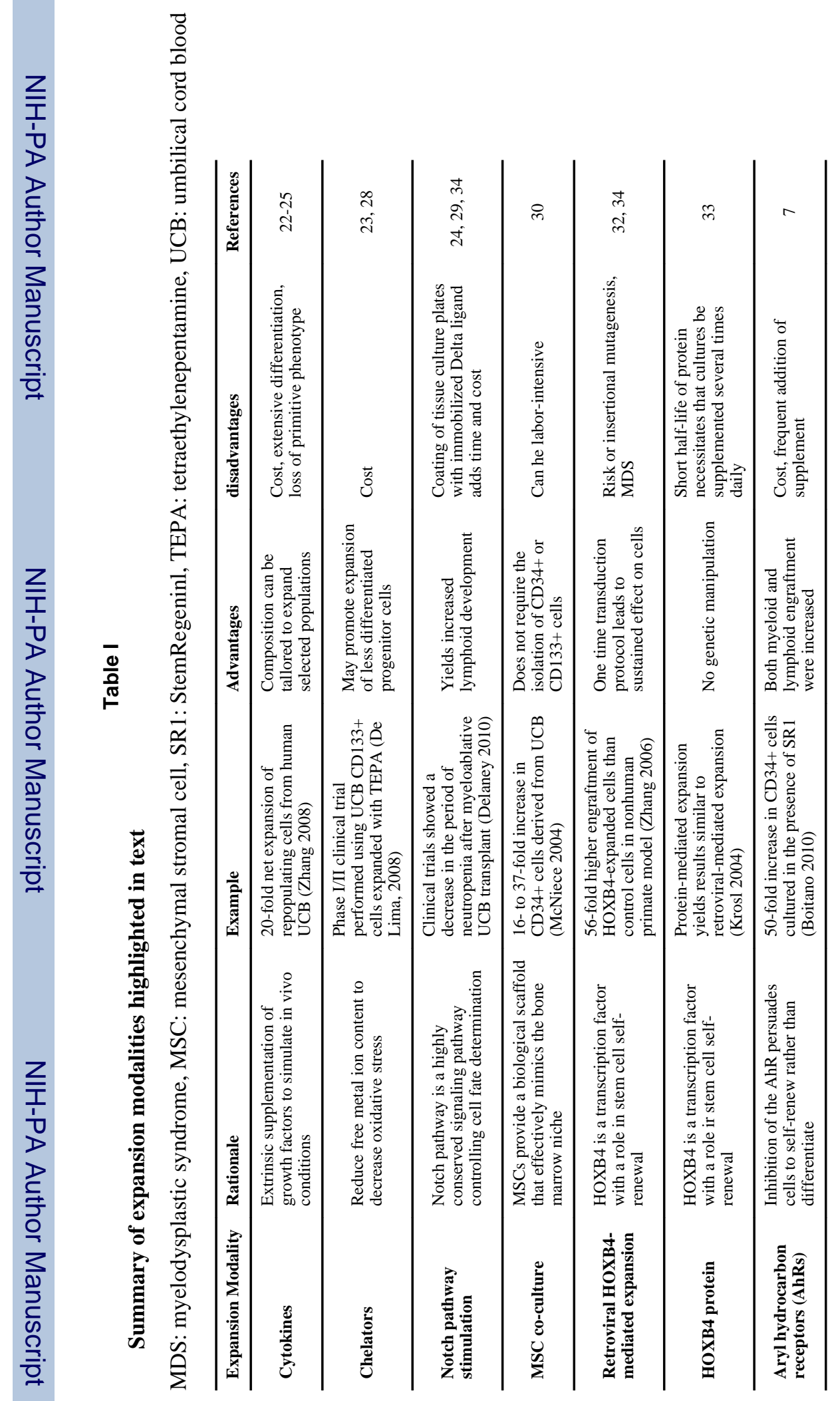

